\title{
Dielectric Behavior of Low Microwave Loss Unit Cell for All Dielectric Metamaterial
}

\author{
Tianhuan Luo, ${ }^{1}$ Bo Li, ${ }^{1}$ Qian Zhao, ${ }^{2}$ and Ji Zhou ${ }^{3}$ \\ ${ }^{1}$ Advanced Materials Institute, Shenzhen Graduate School, Tsinghua University, Shenzhen 518055, China \\ ${ }^{2}$ State Key Lab of Tribology, Department of Mechanical Engineering, Tsinghua University, Beijing 100084, China \\ ${ }^{3}$ State Key Lab of New Ceramics and Fine Processing, Department of Materials Science and Engineering, Tsinghua University, \\ Beijing 100084, China
}

Correspondence should be addressed to Bo Li; boli@mail.tsinghua.edu.cn and Qian Zhao; zhaoqian@tsinghua.edu.cn

Received 9 December 2014; Accepted 29 January 2015

Academic Editor: Roman E. Noskov

Copyright (c) 2015 Tianhuan Luo et al. This is an open access article distributed under the Creative Commons Attribution License, which permits unrestricted use, distribution, and reproduction in any medium, provided the original work is properly cited.

\begin{abstract}
With a deep study of the metamaterial, its unit cells have been widely extended from metals to dielectrics. The dielectric based unit cells attract much attention because of the advantage of easy preparation, tunability, and higher frequency response, and so forth. Using the conventional solid state method, we prepared a kind of incipient ferroelectrics (calcium titanate, $\mathrm{CaTiO}_{3}$ ) with higher microwave permittivity and lower loss, which can be successfully used to construct metamaterials. The temperature and frequency dependence of dielectric constant are also measured under different sintering temperatures. The dielectric spectra showed a slight permittivity decrease with the increase of temperature and exhibited a loss of 0.0005 , combined with a higher microwave dielectric constant of $\sim 167$ and quality factor $Q$ of 2049. Therefore, $\mathrm{CaTiO}_{3}$ is a kind of versatile and potential metamaterial unit cell. The permittivity of $\mathrm{CaTiO}_{3}$ at higher microwave frequency was also examined in the rectangular waveguide and we got the permittivity of 165 , creating a new method to test permittivity at higher microwave frequency.
\end{abstract}

\section{Introduction}

Since increasing attention has been paid to metamaterials due to their novel physical behaviors and versatile applications, such as left-handed metamaterials (LHMs) using split ring resonators (SRRs) and metal wire arrays to produce negative effective permeability and negative permittivity, respectively $[1,2]$, more and more outstanding ceramic materials such as $\mathrm{Ba}_{x} \mathrm{Sr}_{1-x} \mathrm{TiO}_{3}$ (BST) are being developed and utilized to build some supernormal materials and structures, such as ferromagnetic/ferroelectric composite metamaterial (CMM) with BST rods [3], Mie resonance structures using dielectric BST particles $[4,5]$, the prism of negative refraction in BST columns [6], and artificial magnetic conductor with high dielectric BST arrays applied in antenna and radar [7], opening a better and more potential approach to construct various isotropic metamaterials, suitable for higher operating frequencies [4]. Although BST has been successfully applied to construct metamaterials, its higher dielectric loss of 0.001 [8] limits its realization of further novel properties.
Therefore, a substitute of the dielectric material needs to be developed and studied. To verify its excellent dielectric properties, systemic research on $\mathrm{CaTiO}_{3}$ was accomplished, mainly in two different ways including variation of dielectric constant against frequency in operating frequency range $\left(10^{6} \mathrm{~Hz} \sim 10^{10} \mathrm{~Hz}\right)$ and against temperature within $-65^{\circ} \mathrm{C} \sim$ $120^{\circ} \mathrm{C}$, respectively.

\section{Experimental Details}

To gain simplification, $\mathrm{CaTiO}_{3}$ ceramic was synthesized through conventional solid state method. All the raw powders were mixed by ball milling with zirconia media in deionized water for $30 \mathrm{~h}$. The powders were pestled in agate mortar after drying, sieved through 50 or 60 mesh sieve. Then, PVA (polyvinyl alcohol, $5 \mathrm{wt} \%$ ) was added to the sieved powders as organic binder to make the formation of the cylinder of $10 \mathrm{~mm}$ in diameter and $1-6 \mathrm{~mm}$ in height by uniaxial compression at $4 \mathrm{MPa}$ with the customized mould. Finally 
the cylinders were sintered at 5 or 6 kinds of temperature in the range from $1250^{\circ} \mathrm{C}$ to $1400^{\circ} \mathrm{C}$ after PVA was volatilized at $600^{\circ} \mathrm{C}$, the temperature increasing rate of which is around $3^{\circ} \mathrm{C} / \mathrm{min}$.

To catch the knowledge of density variation, Archimedes drainage method was taken, to measure the size and weight of specimen as well. To explore the phase structure, X-ray diffraction (XRD-7000 X, SHIMADZU) analysis with Cu$\mathrm{K} \alpha$ radiation was available and accessible. The morphology and microstructure were evaluated by scanning electron microscopy (SEM) with energy dispersive spectroscopy (EDS) (JSM-7001F, JEOL) on the as-sintered and fractured surfaces. To make the microstructure much more persuasive, the JSM-6460LV, JEOL (SEM), were also utilized to verify the previous pictures. The dielectric properties were measured using the impendence analyzers Agilent HP 4192A (5 Hz $13 \mathrm{MHz})$, and Agilent E4991A (1 MHz 3 GHz). The 4192A measurements were performed at temperatures ranging from $-65^{\circ} \mathrm{C}$ to $120^{\circ} \mathrm{C}$ and at the same time loaded with six different frequencies containing $10 \mathrm{kHz}, 100 \mathrm{kHz}, 200 \mathrm{kHz}, 500 \mathrm{kHz}$, $800 \mathrm{kHz}$, and $1 \mathrm{MHz}$. The higher frequency dielectric properties were tested by an Agilent HP 8720ES S-Parameter network analyzer $(50 \mathrm{MHz} 20 \mathrm{GHz})$ using the Hakki and Coleman dielectric resonator method [9] with the $\mathrm{TE}_{011}$ [10] and $\mathrm{TE}_{01 \delta}$ [11] resonant mode of dielectric resonators excited, measuring the permittivity (including resonant frequency $f$ ) and unloaded $Q$ factor (containing $Q * f$ ), respectively. Besides, to gain more understanding of higher microwave frequency behavior, as depicted in Figure 1, we simulated the $S$-parameter of transmission $\left(S_{21}\right)$ and reflection $\left(S_{11}\right)$ of the dielectric cube with Perfect Electric (PE) and Perfect Magnetic (PM) boundary conditions along $x$ and $y$ directions, respectively. And the propagation direction of electromagnetic wave should be along $z$ direction. Finally the prepared single cube $\mathrm{CaTiO}_{3}$ in $2 \times 2 \times 2 \mathrm{~mm}$ was examined in a rectangular waveguide by the network analyzer. Through comparing the simulation and experiment results, we can capture the permittivity of the dielectric ceramic, which has provided a new method to examine the dielectric constant on higher microwave frequency.

\section{Results and Discussion}

3.1. XRD Plots. Each dielectric ceramic sample has its own structure and lattice information through series of X-ray diffraction experiments of different sintering temperatures. To determine the phase of the synthesized samples, the Xray diffraction patterns are measured and shown in Figure 2, which clearly shows orthorhombic structure for $\mathrm{CaTiO}_{3}$ in incipient ferroelectric phase [12]. It has been proved that $\mathrm{CaTiO}_{3}$ sintered at $1350^{\circ} \mathrm{C}$ has the same lattice structure as the unsintered ones (JCPDS number 42-0423, Pnma(62), $a=$ $5.442 \AA, b=7.642 \AA, c=5.381 \AA$ ), while being different from the other ceramics sintered at $1250^{\circ} \mathrm{C}, 1300^{\circ} \mathrm{C}$, and $1400^{\circ} \mathrm{C}$ (JCPDS number 22-0153, Pnma(62), $a=5.440 \AA, b=7.644 \AA$, $c=5.381 \AA$ ). The alteration of lattice parameters would be probably related to the appearance of defects due to the distortion in the $\mathrm{CaTiO}_{3}$ lattice [13]. The red line $\left(1350^{\circ} \mathrm{C}\right)$ and

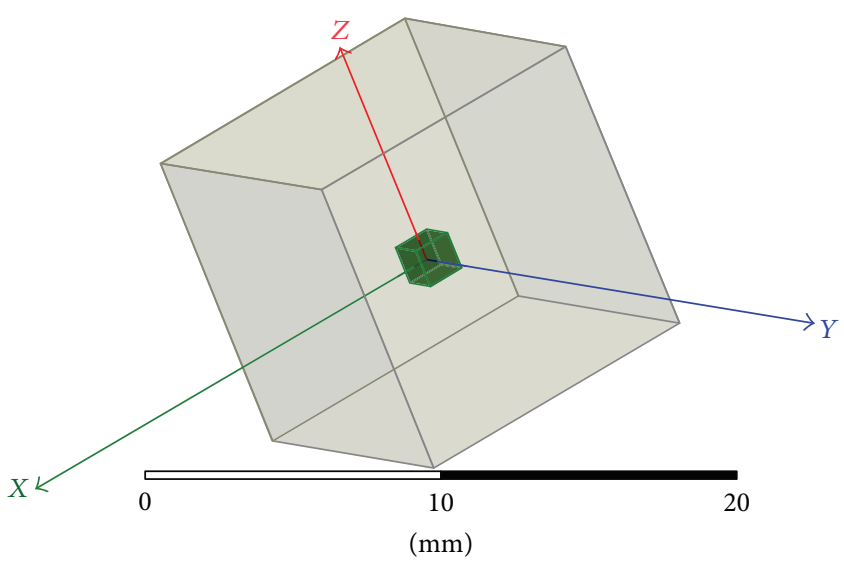

FIgURE 1: The simulation model of dielectric ceramic cube by $2 \times 2 \times$ $2 \mathrm{~mm}$.

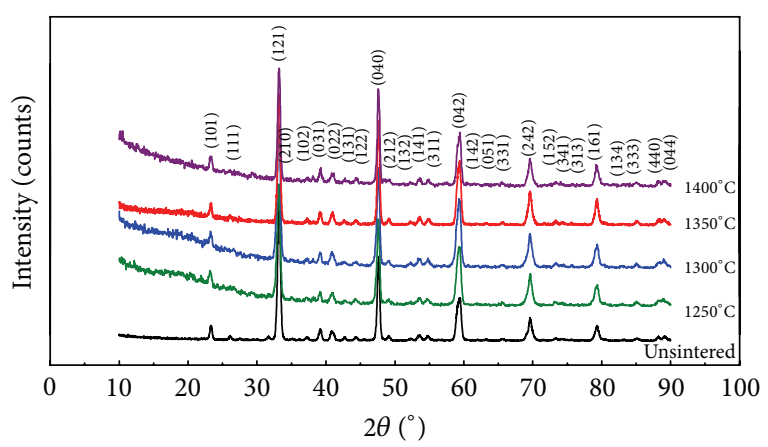

FIGURE 2: XRD patterns of $\mathrm{CaTiO}_{3}$ ceramics fabricated under different sintering conditions, with respect to unsintered ones, $1250^{\circ} \mathrm{C}$, $1300^{\circ} \mathrm{C}, 1350^{\circ} \mathrm{C}$, and $1400^{\circ} \mathrm{C}$, respectively.

black line (unsintered) have the similar diffraction situation, distinguishing from the rest sintering temperatures with slopes for the small diffraction degree.

3.2. Basic Physical Properties. To make sure the preparation process was excellent and the macrostructure was dense enough, the volume shrinkage and relative density measurement were applied to those samples of different sintering temperatures. Because the ceramic particles were combined with adhesive PVA, the volume and density would be changed after the sintering process. The most dense structure corresponded to best sintering temperature. As Figure 3 revealed, in this experiment, the best sintering temperature was $1350^{\circ} \mathrm{C}$, at which the $\mathrm{CaTiO}_{3}$ captured the largest volume shrinkage of $34.78 \%$ and the highest relative density of $97.88 \%$.

3.3. SEM. Not only the macrostructure should be dense enough, but also the microstructure should have less defects to win a better dielectric behavior. Figure 4 shows the microstructures of $\mathrm{CaTiO}_{3}$ ceramics on surface and section parts. From the surface and section, the most dense one was allied with Figure 4(c) occupying an average particle size of $3 \mu \mathrm{m}$. More pores had the presence in the phase in Figures 4(a) and 4(b), with a larger particle size in Figure 4(d). As 


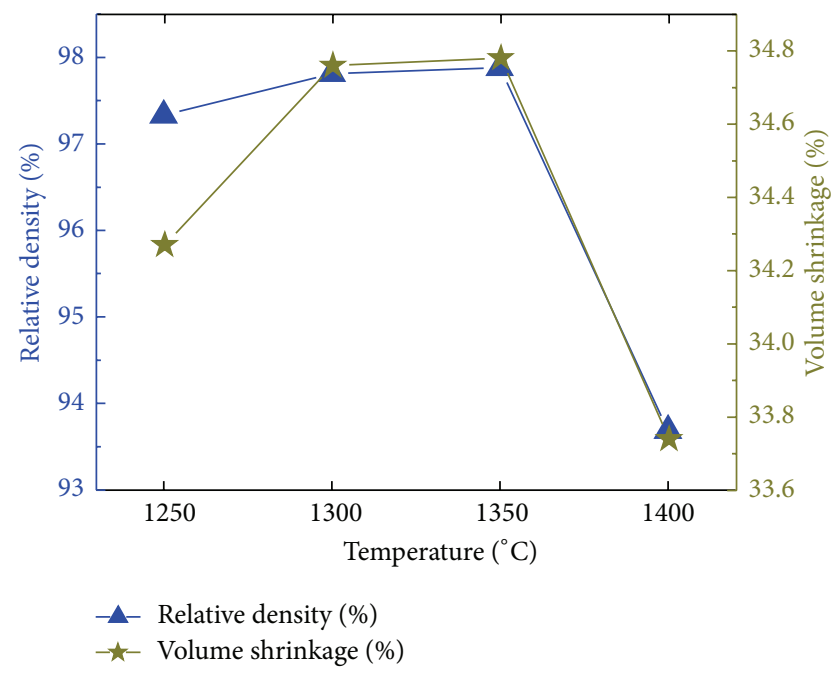

FIGURE 3: The volume shrinkage and relative density alteration of $\mathrm{CaTiO}_{3}$ against sintering temperature.

the sintering temperature increased, the number of defects decreased until the most suitable temperature $\left(1350^{\circ} \mathrm{C}\right)$ with the most dense phase and the least pores and disorder. Above the most fitting temperature, ceramic particles would grow up and gas cavity became larger, resulting in a deep property decline.

\subsection{Dielectric Properties}

(i) The Frequency Dependence of Dielectric Constant. Since the application is concerned with metamaterial at microwave frequency, the frequency dependence of permittivity has to be uncovered. Just as shown in Figure 5, the lowest dielectric constant and less variable dielectric variation in sintering temperature of $1350^{\circ} \mathrm{C}$ came out, and a deep dielectric drop from 470 to 167 turned up in $10^{6} \mathrm{~Hz} \sim 10^{9} \mathrm{~Hz}$ range. Above $10^{9} \mathrm{~Hz}$, the dielectric constant remained almost invariable around 167. Compared with the best sintering condition of $1350^{\circ} \mathrm{C}$ with less variable permittivity situation, the frequency dependence of the permittivity of $1250^{\circ} \mathrm{C}, 1300^{\circ} \mathrm{C}$, and $1400^{\circ} \mathrm{C}$ was much more unstable. As for $\mathrm{CaTiO}_{3}$, it has its own dielectric response mechanism. According to Tian [14], electronic relaxation polarization plays an important role in $10^{6} \sim 10^{9} \mathrm{~Hz}$ range, as well as electronic and ionic displacement polarization during $10^{9} \sim 10^{10} \mathrm{~Hz}$. In $10^{6} \sim 10^{9} \mathrm{~Hz}$ frequency range, the electron energy state has changed and weakly bounded electrons are formed in partial energy levels of band gap owning to the thermal vibration of crystal lattice, defects, and impurities. The weakly bounded electrons are shared among surrounding cations and can be activated through absorbing more energy from the lattice thermal vibration and jump from lower local energy level to higher energy level. Thus, the weakly bounded electrons move from one cation to another. And their distribution in short distance will gain direction when loaded with electric field, which is just the electronic relaxation polarization. If the frequency of electric field becomes higher, the directional distribution of weakly
TABLE 1: Microwave dielectric properties of $\mathrm{CaTiO}_{3}$ at different sintering temperatures.

\begin{tabular}{lccccc}
\hline $\begin{array}{l}\text { Sintering } \\
T /{ }^{\circ} \mathrm{C}\end{array}$ & $f(\mathrm{GHz})$ & $\varepsilon_{r}$ & $\tan D$ & $Q$ & $Q \times f(\mathrm{GHz})$ \\
\hline 1250 & 3.200 & 169.53 & 0.0006 & 1605 & 4188 \\
1300 & 3.200 & 169.21 & 0.0006 & 1803 & 5022 \\
1350 & 3.200 & 167.99 & 0.0005 & 2049 & 5219 \\
1400 & 3.200 & 167.15 & 0.001 & 785 & 2063 \\
\hline
\end{tabular}

bounded electrons will be weakened and the polarization value will also decline. Therefore, the dielectric constant has a negative frequency dependence among $10^{6} \sim 10^{9} \mathrm{~Hz}$. Above $10^{9} \mathrm{~Hz}$, the electronic relaxation polarization does not exist, but the electronic and ionic displacement polarization determine the main polarization mode. However, as we all know, the relative displacements between electrons and nuclei, as well as those between anions and cations, are much limited due to the strong attraction. So the dielectric constant is almost invariable with slightly increasing as the frequency increases from $10^{9} \mathrm{~Hz}$, which would be the excellent microwave dielectric behaviors. What is more, the situation of the lower permittivity of the sintering temperature at $1350^{\circ} \mathrm{C}$, compared with the rest sintering conditions, can be easily understood because of more defects existing in the samples of the sintering temperatures at $1250^{\circ} \mathrm{C}, 1300^{\circ} \mathrm{C}$, and $1400^{\circ} \mathrm{C}$ (defects shown in Figure 4 and reflected in Figures 2 and 3) and contributing to the polarization.

Because this kind of ceramic is specially of the metamaterials working in microwave frequency range, the measurements of microwave dielectric properties were taken, with the resonant frequency (choosing $3.2 \mathrm{GHz}$ ), dielectric constant, dielectric loss, quality factor, and parameter $Q \times f$, listed in Table 1. Around frequency $3.2 \mathrm{GHz}$, the dielectric constant kept slightly decreasing but almost in the same level. The highest $Q$ (2049), $Q \times f$ (5219), and lowest dielectric loss (0.0005) were also ascribed to its dense structure and fewer defects, with the sintering temperature of $1350^{\circ} \mathrm{C}$ $[15,16]$. Apparently, the dielectric properties of sintering temperature $1400^{\circ} \mathrm{C}$ had dropped down a lot owing to the deterioration under the higher temperature. Compared with previous papers involving the dielectric metamaterial, $\mathrm{CaTiO}_{3}$ has much advantage of the lower dielectric loss. This kind of low loss mainly arises from its better interior microstructure and preparation approach. And its structure type (orthorhombic) will affect its forming condition (such as the sintering temperature) and further contribute to the preparation process to some extent $[12,17]$. In addition, the value of permittivity and dielectric loss can be tuned by altering the compositions of ceramics, introducing new components, or doping some additives, such as $\mathrm{ZrO}_{2}$ [18] and $\mathrm{CeO}_{2}$ [19], which will decrease and increase the permittivity of $\mathrm{CaTiO}_{3}$, respectively, and decrease the loss tangent value in some way.

(ii) The Temperature Dependence of Dielectric Constant. Since we have known the frequency dependence of permittivity, another significant task that needs to be done is that we 
Surface
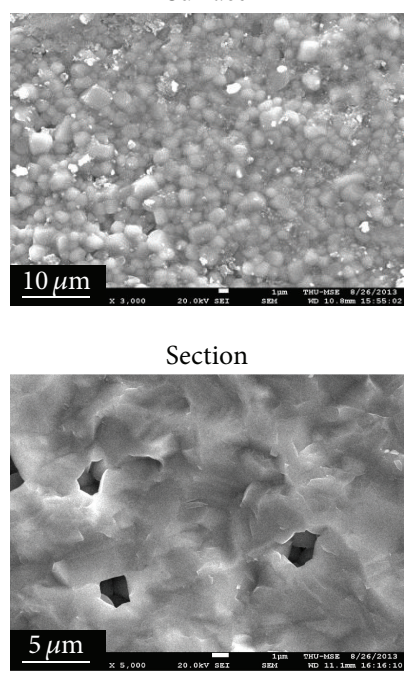

(a)
Surface

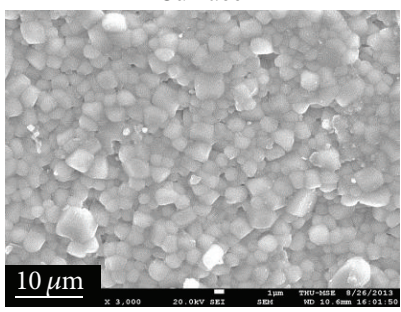

Section

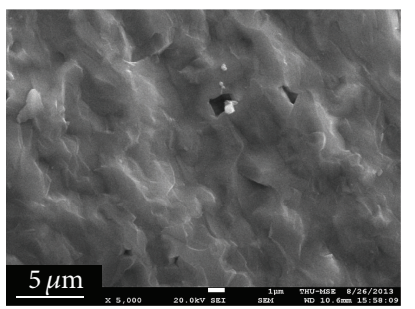

(b)
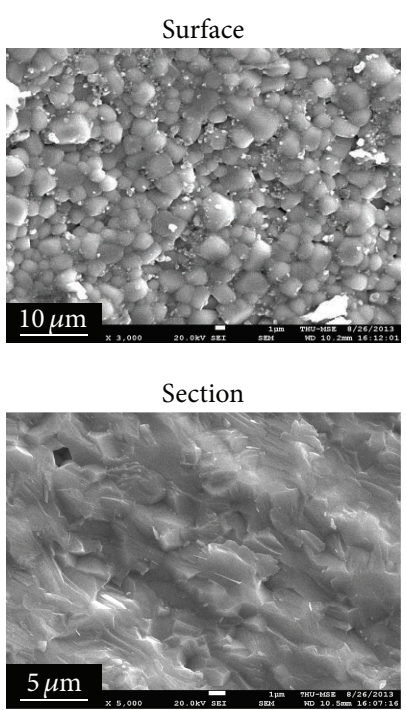

(c)
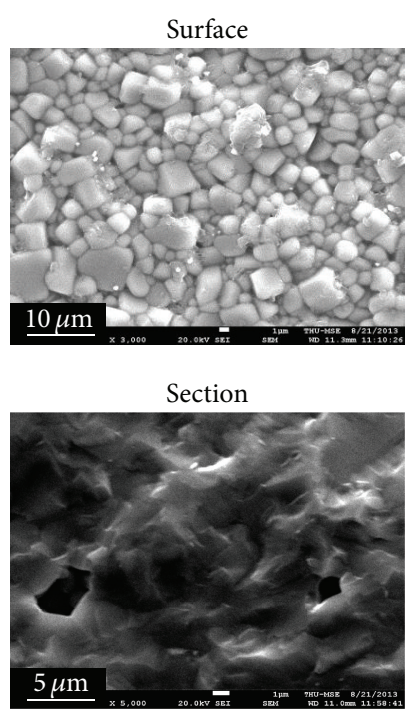

(d)

Figure 4: Images of Scanning Electron Microscope at different sintering temperatures for $\mathrm{CaTiO}_{3}$ at (a) $1250^{\circ} \mathrm{C}$, (b) $1300^{\circ} \mathrm{C},(\mathrm{c}) 1350^{\circ} \mathrm{C}$, and (d) $1400^{\circ} \mathrm{C}$ by surface and section.

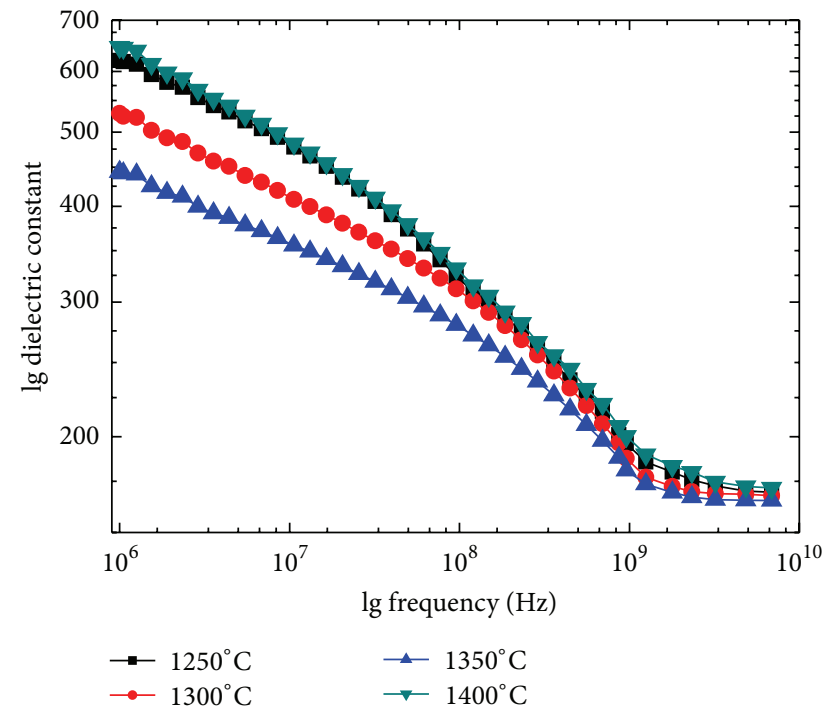

FIgURE 5: Dielectric constant variation against frequency at $25^{\circ} \mathrm{C}$ for $\mathrm{CaTiO}_{3}$ sintered at $1250^{\circ} \mathrm{C}, 1300^{\circ} \mathrm{C}, 1350^{\circ} \mathrm{C}$, and $1400^{\circ} \mathrm{C}$, respectively.

should study the temperature dependence of permittivity to reveal the variation of dielectric constant. The similar situations for each sintering temperature are displayed in Figure 6, where the decreasing dielectric constant existed when the temperature increased. This should be interpreted by the theory of Bosman and Havinga [20, 21], improved by Bartels and Smith [22], saying that the temperature dependence of permittivity is negative when $\varepsilon_{r}>20$. Furthermore, the sintering temperature of $1350^{\circ} \mathrm{C}$ made $\mathrm{CaTiO}_{3}$ occupy a slight dielectric constant descending around 475 . The phenomenon of possessing larger dielectric constant in the sintering temperatures of $1250^{\circ} \mathrm{C}, 1300^{\circ} \mathrm{C}$, and $1400^{\circ} \mathrm{C}$

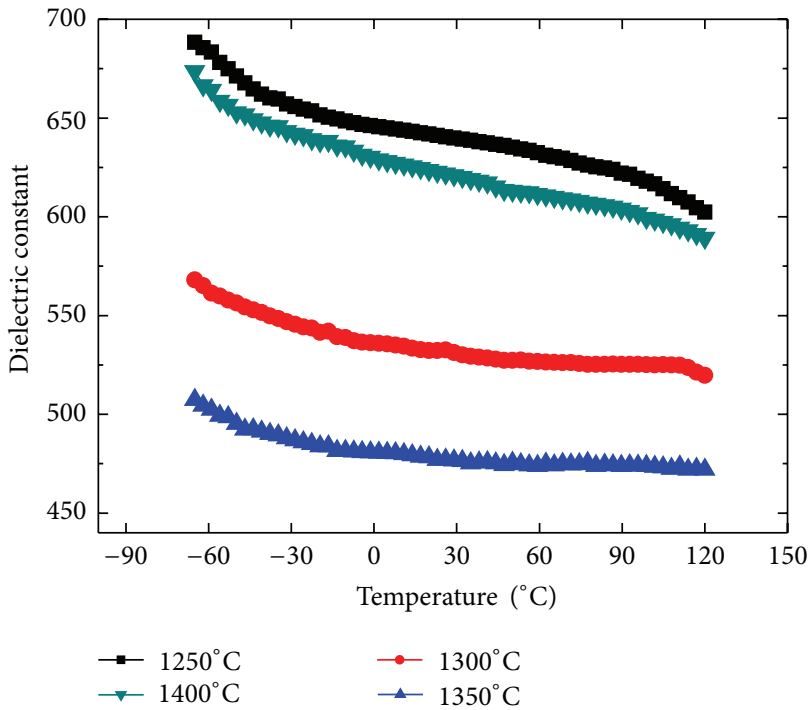

Figure 6: Dielectric constant variation against temperature at $500 \mathrm{kHz}$ for $\mathrm{CaTiO}_{3}$, sintered at $1250^{\circ} \mathrm{C}, 1300^{\circ} \mathrm{C}, 1350^{\circ} \mathrm{C}$, and $1400^{\circ} \mathrm{C}$, respectively.

would also be attributed to the defects, contributing effective electric charge, adding the polarization possibility, and finally resulting in improved permittivity.

3.5. Permittivity Tested at Higher Microwave Frequency. To get further comprehension of the higher frequency resonance of $\mathrm{CaTiO}_{3}$, a method was utilized to examine and retrieve the permittivity, based on the fact that the limited measuring technology and fewer methods could test the dielectric constant around or above $10^{10} \mathrm{~Hz}$. The new method is to put 


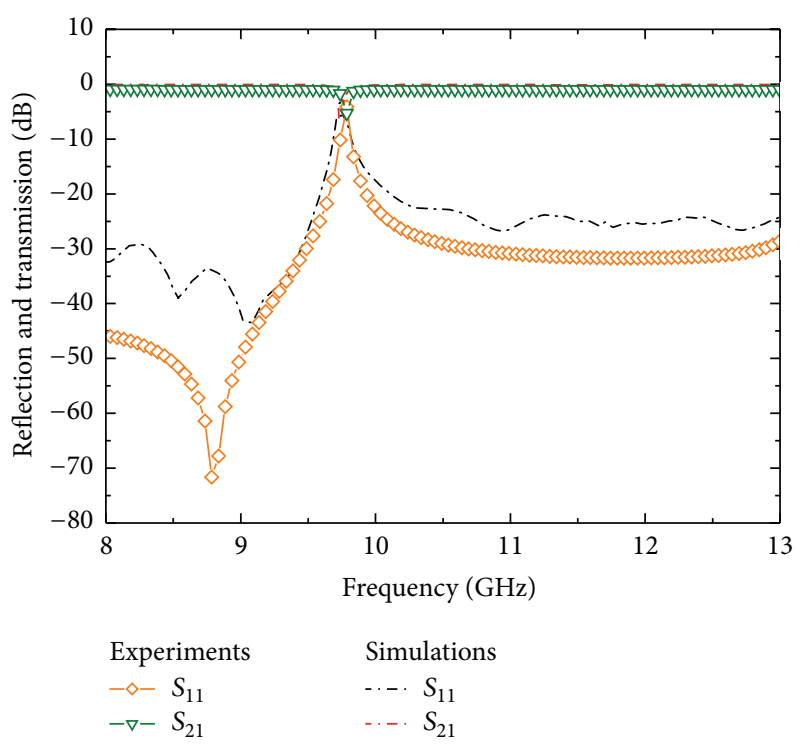

Figure 7: $\mathrm{CaTiO}_{3}$ cube by $2 \times 2 \times 2 \mathrm{~mm}$ was tested in waveguide with the magnitude of $S$ parameter: $S_{21}$ of transmission and $S_{11}$ of reflection, including the comparison of simulations and experiments on $S_{11}$ and $S_{21}$.

the single cube of $2 \times 2 \times 2 \mathrm{~mm}$ specimen into a rectangular waveguide and measure the microwave $S$-Parameter of transmission $\left(S_{21}\right)$ and reflection $\left(S_{11}\right)$ and phase of $S_{21}$ by an HP8720ES network analyzer. As mentioned in [4], the first resonance frequency is completely determined by dielectric constant. We can get the permittivity of the dielectric ceramics through comparing the computer simulation using the finite-difference time domain solver and experimental results from the testing in the rectangular waveguide. As demonstrated in Figure 7, the experiments and simulations of the $S$-Parameter have a great correspondence and consistency in the range from $8 \mathrm{GHz}$ to $13 \mathrm{GHz}$. Around $9.8 \mathrm{GHz},-3.3 \mathrm{~dB}$ for $S_{11}$ simulated and $-3.6 \mathrm{~dB}$ for $S_{11}$ in experiment were observed, as well as $-11 \mathrm{~dB}$ for $S_{21}$ simulated and $-5.6 \mathrm{~dB}$ for $S_{21}$ in experiment. Finally, we have got the permittivity of $\mathrm{CaTiO}_{3}$ for around 165, which is extremely close to the microwave testing result.

\section{Conclusion}

Through systemic experiments, $\mathrm{CaTiO}_{3}$ was fabricated by solid state method under better suitable sintering temperature of $1350^{\circ} \mathrm{C}$ with a volume shrinkage of $34.78 \%$, relative density of $97.88 \%$, which is better than the value of $95 \%$ [12]. The X-ray diffraction and SEM had shown a perovskite orthorhombic structure and a dense crystal microstructure. The dielectric spectra revealed a deep dielectric drop from 470 to 167 in the range $10^{6} \mathrm{~Hz} \sim 10^{9} \mathrm{~Hz}$ and exhibited a lower microwave loss of 0.0005 , combined with a higher microwave dielectric constant of $\sim 167$ and microwave quality factor $Q$ of 2049 and $Q \times f$ of $5219 \mathrm{GHz}$, respectively. Also slight decrease versus temperature for the permittivity was investigated systemically. The single cube $\mathrm{CaTiO}_{3}$ with a size of $2 \times 2 \times 2 \mathrm{~mm}$ was examined in a rectangular waveguide from $8 \mathrm{GHz}$ to $13 \mathrm{GHz}$, with a resonant frequency of $9.8 \mathrm{GHz}$, which agrees with the simulation. We got the permittivity of 165 for $\mathrm{CaTiO}_{3}$ at higher microwave frequency, very close to the microwave result of $\sim 167$. Therefore, $\mathrm{CaTiO}_{3}$ is a kind of versatile and potential metamaterial unit cell and a new dielectric examination method is created.

\section{Conflict of Interests}

The authors declare that there is no conflict of interests regarding the publication of this paper.

\section{Acknowledgments}

This work is supported by the National High Technology Research and Development Program of China (Grant no. 2012AA030403), the National Natural Science Foundation of China (Grant nos. 61275176 and 51032003), and the Science and Technology Plan of Shenzhen City of China (Grant nos. JCYJ20120619152711509 and JC201105180802A). Acknowledgment also goes to Professor Fuli Zhang for his helpful guidance and corrections of the paper. The appreciation of assisting in experiments is attributed to Hongya $\mathrm{Wu}$, Xiaoming Liu, and Chuwen Lan, and so forth.

\section{References}

[1] J. B. Pendry, A. J. Holden, W. J. Stewart, and I. Youngs, "Extremely low frequency plasmons in metallic mesostructures," Physical Review Letters, vol. 76, no. 25, pp. 4773-4776, 1996.

[2] J. B. Pendry, A. J. Holden, D. J. Robbins, and W. J. Stewart, "Magnetism from conductors and enhanced nonlinear phenomena," IEEE Transactions on Microwave Theory and Techniques, vol. 47, no. 11, pp. 2075-2084, 1999.

[3] H. J. Zhao, L. Kang, J. Zhou et al., "Experimental demonstration of tunable negative phase velocity and negative refraction in a ferromagnetic/ferroelectric composite metamaterial," Applied Physics Letters, vol. 93, no. 20, Article ID 201106, 2008.

[4] Q. Zhao, J. Zhou, F. L. Zhang, and D. Lippens, "Mie resonancebased dielectric metamaterials," Materials Today, vol. 12, no. 12, pp. 60-69, 2009.

[5] Q. Zhao, L. Kang, B. Du et al., "Experimental demonstration of isotropic negative permeability in a three-dimensional dielectric composite," Physical Review Letters, vol. 101, no. 2, Article ID 027402, 2008.

[6] Y. Z. Sun, Y. F. Sun, L. X. Ran, W. G. Wang, L. Peng, and Q. L. Chen, "Experimental verification on negative refraction of BST," Scientia Sinica Physica, Mechanica \& Astronomica, vol. 40, no. 12, pp. 1476-1481, 2010.

[7] F. L. Zhang, D. Lippens, and A. L. Borja, "Low profile small antenna using ferroelectrics cube based artificial magnetic conductor," in Proceedings of the 4th European Conference on Antennas and Propagation (EuCAP '10), April 2010.

[8] L. C. Sengupta and S. Sengupta, "Breakthrough advances in low loss, tunable dielectric materials," Materials Research Innovations, vol. 2, no. 5, pp. 278-282, 1999.

[9] B. W. Hakki and P. D. Coleman, "A dielectric resonator method of measuring inductive capacities in the millimeter range," $R E$ 
Transactions on Microwave Theory and Techniques, vol. 8, no. 4, pp. 402-410, 1960.

[10] W. E. Courtney, "Analysis and evaluation of a method of measuring the complex permittivity and permeability microwave insulators," IEEE Transactions on Microwave Theory and Techniques, vol. 18, no. 8, pp. 476-485, 1970.

[11] J. Krupka, K. Derzakowski, B. Riddle, and J. B. Jarvis, "A dielectric resonator for measurements of complex permittivity of low loss dielectric materials as a function of temperature," Measurement Science and Technology, vol. 9, no. 10, pp. 17511756, 1998.

[12] V. V. Lemanov, A. V. Sotnikov, E. P. Smirnova, M. Weihnacht, and R. Kunze, "Perovskite $\mathrm{CaTiO}_{3}$ as an incipient ferroelectric," Solid State Communications, vol. 110, no. 11, pp. 611-614, 1999.

[13] L. S. Cavalcante, V. S. Marques, J. C. Sczancoski et al., "Synthesis, structural refinement and optical behavior of $\mathrm{CaTiO}_{3}$ powders: a comparative study of processing in different furnaces," Chemical Engineering Journal, vol. 143, no. 1-3, pp. 299-307, 2008.

[14] S. Tian, Physical Properties of Materials, Beihang University Press, Beijing, China, 2001.

[15] A. Pashkin, S. Kamba, M. Berta et al., "High frequency dielectric properties of $\mathrm{CaTiO}_{3}$-based microwave ceramics," Journal of Physics D: Applied Physics, vol. 38, no. 5, pp. 741-748, 2005.

[16] H. F. Kay and P. C. Bailey, "Structure and properties of $\mathrm{CaTiO}_{3}$," Acta Crystallographica, vol. 10, no. 3, pp. 219-226, 1957.

[17] H. K. Zhu, M. Liu, and H. Q. Zhou, "Effects of additives on $\mathrm{CaTiO}_{3}$ properties," Electronic Components \& Materials, vol. 24, no. 7, 2005.

[18] H. Y. Wu, J. Zhou, C. W. Lan, Y. S. Guo, and K. Bi, "Microwave memristive-like nonlinearity in a dielectric metamaterial," Scientific Reports, vol. 4, p. 5499, 2014.

[19] E. R. Kipkoech, F. Azough, and R. Freer, "The effect of $\mathrm{CeO}_{2}$ on the microstructure and dielectric properties of $\mathrm{CaTiO}_{3}$-based ceramics," European Ceramic Society, vol. 206, no. 2, pp. 22132216, 2002.

[20] E. E. Havinga, "The temperature dependence of dielectric constants," Journal of Physics and Chemistry of Solids, vol. 18, no. 2-3, pp. 253-255, 1961.

[21] A. J. Bosman and E. E. Havinga, "Temperature dependence of dielectric constants of cubic ionic compounds," Physical Review, vol. 129, no. 4, pp. 1593-1600, 1963.

[22] R. A. Bartels and P. A. Smith, "Pressure and temperature dependence of the static dielectric constants of $\mathrm{KCl}, \mathrm{NaCl}, \mathrm{LiF}$, and MgO," Physical Review B, vol. 7, no. 8, pp. 3885-3892, 1973. 

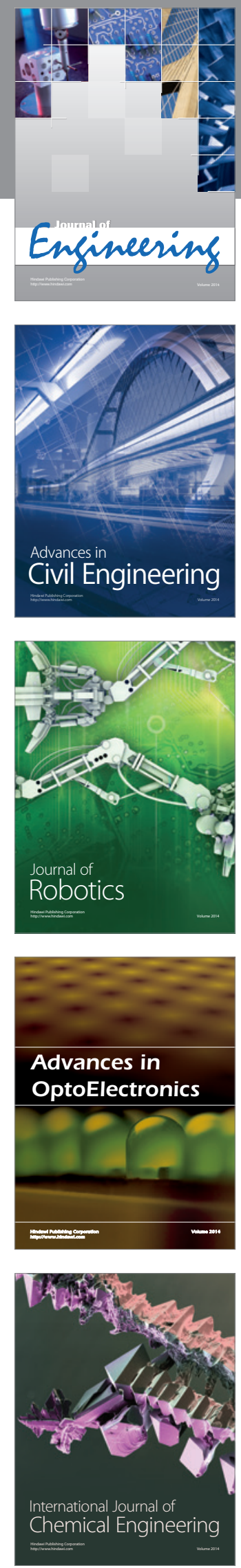

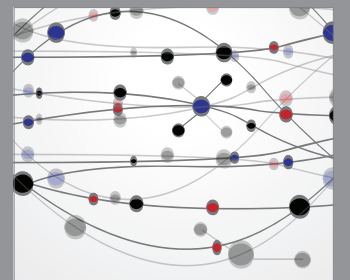

The Scientific World Journal
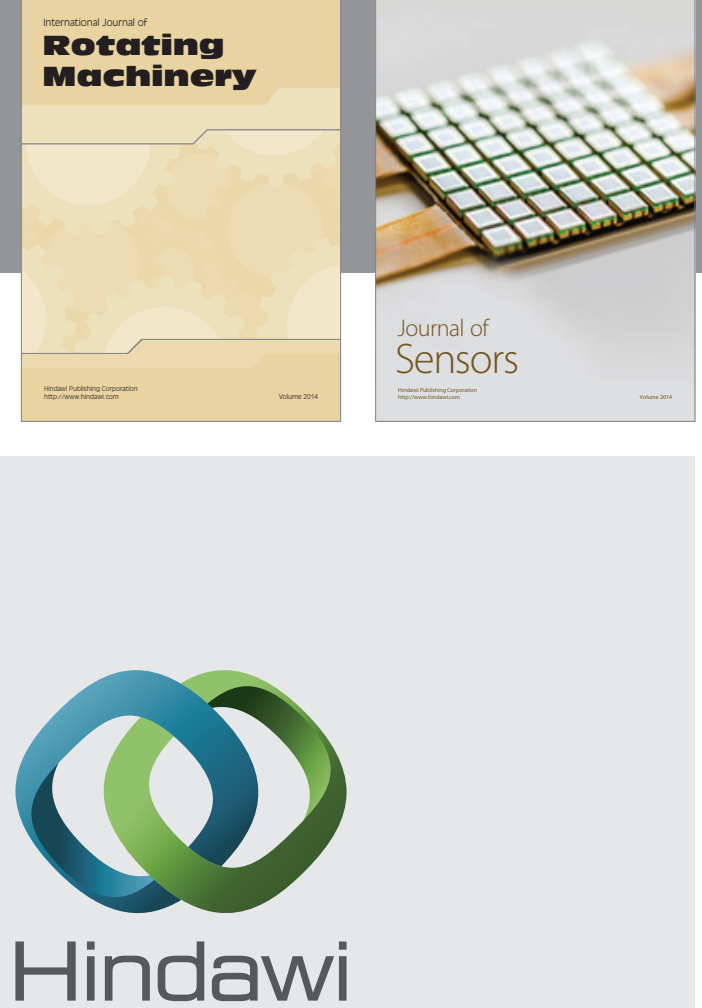

Submit your manuscripts at http://www.hindawi.com
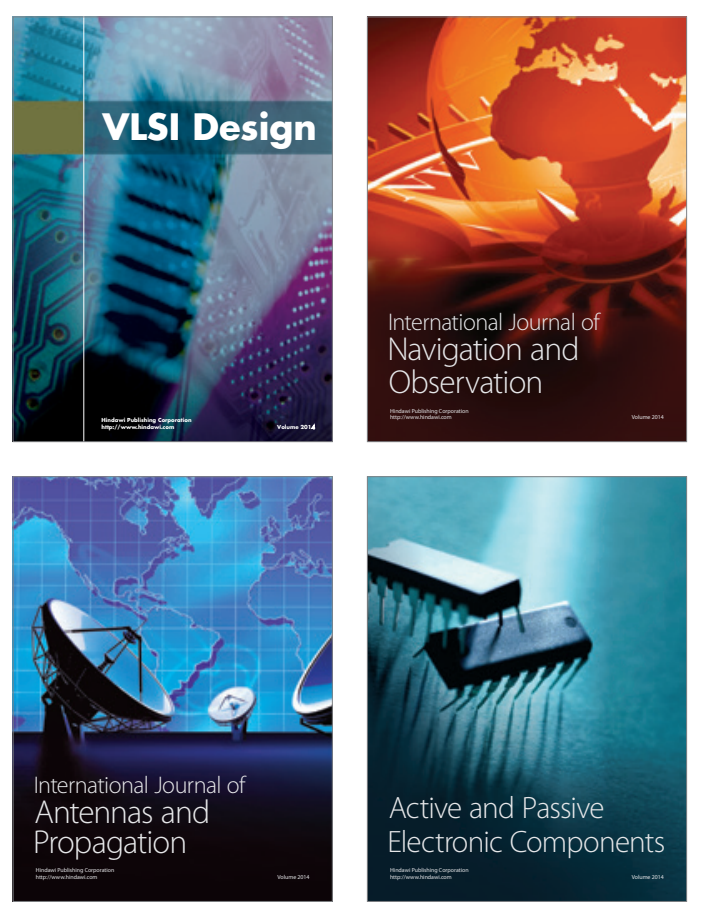
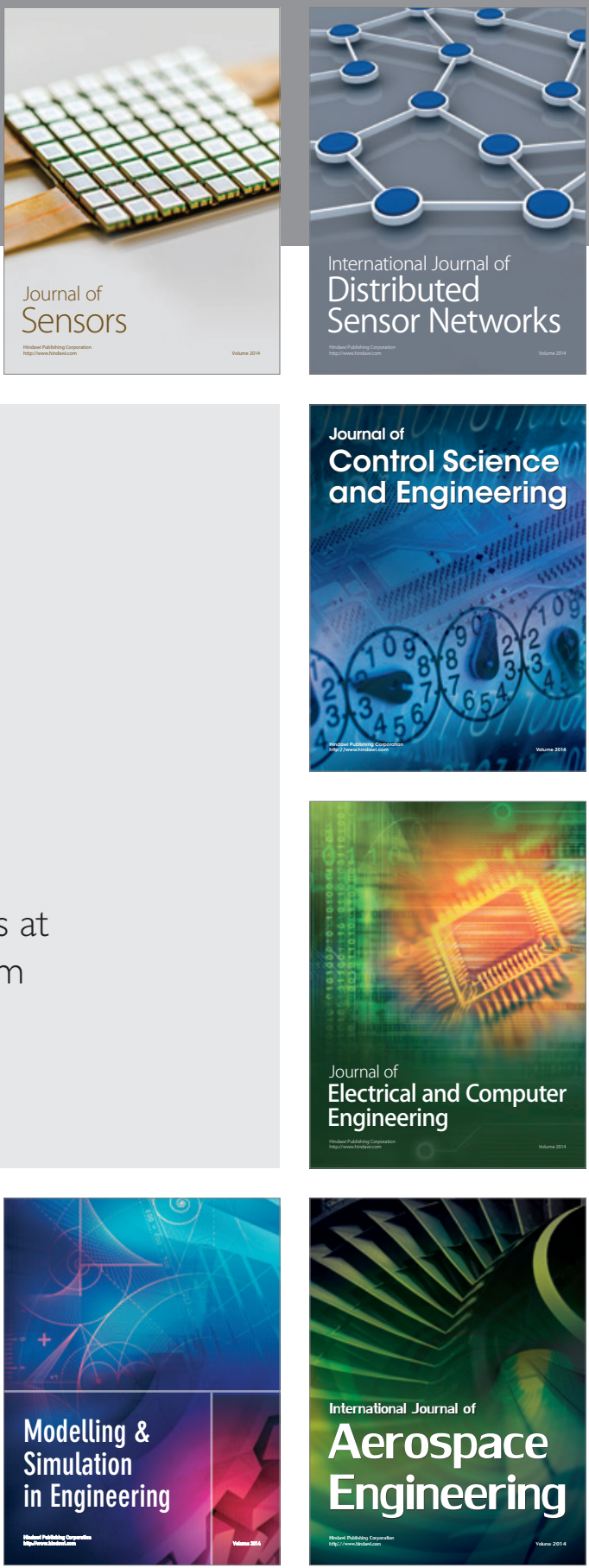

Journal of

Control Science

and Engineering
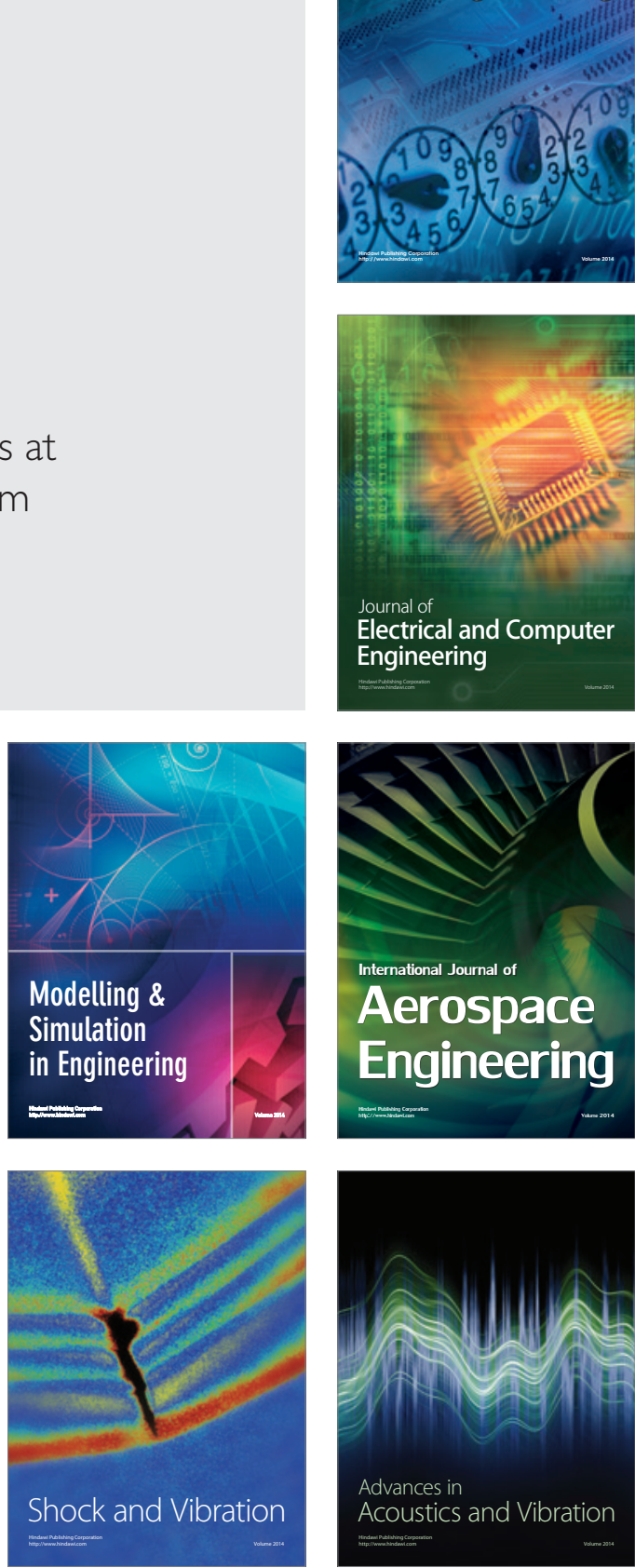